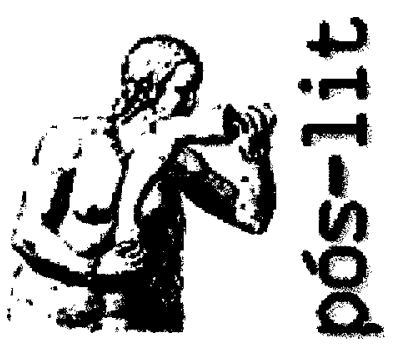

Programa de Pós-Graduação em

Letras: Estudos Literários da Faculdade de Letras da UFMG

Artigo disponível em http://www.letras.ufmg.br/poslit

\section{COSTA LIMA E 0 TEOREMA DO CONTROLE DO FICCIONAL}

Antônia Cristina de Alencar Pires $U F M G$ 
"Não posso saber que valor tudo isso terá, nem muito menos o interesse que poderá despertar (...)."

Luiz Costa Lima in Sociedade e discurso ficcional

\section{INTRODUÇĀO}

Há algum tempo venho reservando uma boa parcela de atenção à obra teórica de Luiz Costa Lima. Vários fatores são responsáveis por isto mas, certamente, o principal deles é o poder de sedução que tal obra desperta com sua capacidade de instigar o leitor, provocar polêmica, suscitar dúvidas, enfim, fabricar argumentos para as discussōes acerca da teoria e da crítica literária.

Espécie de puzzle propiciador de jogos mentais, a obra de Costa Lima é calcada em proposições e silogismos dialéticos, os quais, para serem melhor compreendidos, precisam ser intercalados ou seja, é necessário que o leitor junte os fios discursivos dispersos em seus vários livros para que, ao final, possa chegar a algum resultado. Sua obra resulta interdependente, pois via de regra, um livro complementa o outro. $\mathrm{O}$ crítico constantemente se revê, se reescreve, tece um discurso-rede, faz uma crítica em palimpsesto, como bem adjetiva Eneida Maria de Souza em seu estudo sobre Costa Lima.

Dono de uma alentada produção teórico-crítica, o autor de Pensando nos trópicos se notabiliza pela busca de rigor e de fundamentação sobre tudo o que se propõe discutir. Procura assim amarrar a questão literária com reflexóes contextuais de cunho histórico e filosófico, numa clara demonstração de que é possível se fazer uma crítica contextualizada sem contudo perder de vista o objeto principal de análise, melhor dizendo, o literário, a literatura.

É meu objetivo neste trabalho discutir um ponto essencial da obra do Crítico, o qual costumo chamar: o teorema de Costa Lima. Este ponto é o conceito do veto ou controle do ficcional, que o crítico formula e discute em uma trilogia que compreende $O$ controle do imaginário (1984), Sociedade e discurso ficcional (1986) e O fingidor e o censor: no Ancien Régime, no
Iluminismo e hoje (1988). Aqui será feita uma breve definição do conceito de veto ao ficcional, de sua natureza, seus mecanismos e seus agentes.

Na questão dos agentes, os casos que escolhi para abordar são a corrente desconstrucionista, que tem em Derrida o seu principal representante e a poética de Jorge Luís Borges. A escolha do primeiro prende-se ao fato de que o desconstrucionismo tem norteado grande parte das reflexões teórico-críticas atuais. $\mathrm{O}$ segundo está ligado à questão da literatura latino-americana.

\section{O TEOREMA DE COSTA LIMA}

Para que se defina o conceito "veto ou controle do ficcional" é necessário, antes de tudo, que se busque compreender a diferença entre fictício e ficcional. Costa Lima procura explicitar a distinção existente entre os dois termos na análise que faz sobre a obra de Miguel de Cervantes - o Dom Quixote. Inaugurador da literatura moderna, o romance cervantino diferencia-se do puramente fictício - no caso, as novelas de cavalaria, gênero literário de cujos despojos se alimenta e ao mesmo tempo ironiza - para reconhecer-se ficcional. Esse reconhecimento significa a atualização do exercício crítico no próprio ato de criação; atualização possibilitada pelo distanciamento do autor em relação a seu discurso. Ou nas palavras de Costa Lima:

Contra a ingenuidade suposta pelo fictício, alimentando-se da ilusão indiscriminadora de seu território quanto ao da verdade, oficcional moderno se alimenta da ironia, do distanciamento, da constituição de uma complexidade que, sem afastar o leitor comum, não se lhe entrega como uma forma de ilusionismo.' (Grifo do autor)

O Dom Quixote rompe com a imitatio, com a prática da verossimilhança (a única possibilidade permitida até então ao artista). A ficção, assumindo-se como ficção, aparecerá depois de forma sistematizada no pensamento de F. Schlegel no século XVIII. O insight de Cervantes no século XVII será retomado e teorizado no século XVIII pelo Romantismo alemão.

Ainda que se soubesse como exercício crítico e de construção, o

$$
\text { 1. LIMA, 1986. p. } 58 .
$$


discurso ficcional, assinala o Crítico, era considerado um discurso subordinado ao discurso dominante - o da verdade - configurado na ciência e na razão. Se na Idade Média o discurso dominante era o teológico, nos séculos XVII e XVIII a razão iluminista elege-se como o centro da verdade.

É exatamente aqui que começa a problemática do veto, do controle do ficcional. A ficção, por não apresentar respostas científicas, por não estar comprometida com o protocolo da verdade, por ser antes uma forma lúdica de conhecimento, passa a ser vigiada de perto pelo discurso dominante, que engendra mecanismos e agentes para exercer seu controle. Para o discurso dominante, deixar o ficcional, o literário sem rédeas, significa deixar que a imaginação subjugue a razão e rompa com a semelhança, se torne um desvio da ordem e da harmonia, instaure a diferença. Aos olhos da cultura ocidental, calcada no referencial da cópia fiel e contínua de um modelo previamente estabelecido, nada mais abominável. Daí a necessidade de controlá-lo.

O controle, seja de natureza religiosa ou secularizada, desenvolve mecanismos que atuam dentro do espaço literário. Costa Lima chama a atenção para a diferença entre controle c censura, ressaltando que esta se faz de fora e sobre o discurso literário, enquanto que o controle é mais sutil, uma vez que é feito dentro do espaço ficcional. Os mecanismos controladores aparecem sob a forma de correções, rótulos e auto-censura, os quais domesticam o ficcional e o tornam accitável, tolerável, principalmente quando podem torná-lo um auxiliar do discurso dominante.

As atençōes de Costa Lima sobre a questão do controle se voltam para a América Latina em diversos momentos da elaboração de seu teorema. Em Sociedade e discurso ficcional dois capítulos são dedicados ao tema, o mesmo ocorrendo em $O$ fingidor e o censor. Transpondo a questão do veto para o solo latino-americano, o crítico anuncia que desde a colonização o controle está presente e seu germe veio nas naus que cruzaram o Atlântico trazendo os colonizadores.

Lembro aqui que as coisas não poderiam se passar de outro modo, levando-se em conta que o encontro entre o colonizador europeu e o nativo, habitantes de terras tão diferentes, já representa por si só um encontro de estranhezas, um encontro onde se verifica a existência do Outro, do diferente e o homem daquele tempo estava acostumado até então apenas a reconhecer o Mesmo, o semelhante.
Instalado no continente americano, o colonizador rapidamente procurou forjar mecanismos de controle para assegurar a ordem. É assim que nas colônias hispano-americanas, a princípio, o veto ao ficcional será de natureza religiosa, cujo mecanismo era o teatro catequético e os agentes eram os padres jesuítas. Para demonstrar isso, Costa Lima faz uma minuciosa pesquisa sobre o trabalho de catequese e percebe que a melhor forma de efetivá-la era através do teatro. Assim, não é sem razão que a representação teatral será largamente utilizada pelos jesuítas.

Vários registros atestam a existência desse tipo de manifestação artística entre os povos nativos, como por exemplo, entre os Incas. Essas representações procuravam encenar a mitologia daquelas sociedades, tal como se dava no teatro grego. Percebendo isso, logo os jesuítas trataram de se apropriar dessa forma de representação, trocando as mitologias nativas pela mitologia bíblica, utilizando o teatro como vetor de propagação do catolicismo e da domesticação do bárbaro selvagem.

Um outro momento de controle religioso explícito é mostrado por Costa Lima no caso da soror Juana Inês de la Cruz, a poetisa barroca mexicana. No caso da freira o controle se mostra mais agudo por ela representar uma tripla transgressão: ser mulher, religiosa e praticante das letras. Enquanto prestadora de serviços à Igreja, a freira tem o apoio da instituição mas, quanto a sua lírica, encontra críticas severas. Temendo o Santo Ofício, Juana Inês gradativamente silencia seus versos.

Embora Costa Lima faça distinção entre controle e censura, creio que no caso da poetisa mexicana e em outro exemplo (não citado pelo autor mas que também poderia servir a estas considerações) - o caso de Antonio José, chamado o Judeu, perseguido e julgado pela Inquisição por suas peças teatrais - controle e censura, parece-me, andam de mãos dadas. Pois, quando os mecanismos sutis já não eram eficazes, recorria-se, em última instância, aos tribunais inquisidores.

Retomando o caminho, volto à questão do veto, agora de natureza secular, uma vez que sedimentado o processo colonizador, o espectro religioso dá lugar às instituições leigas ou pelo menos sai da cena principal para ocupar os bastidores. Para examinar a natureza leiga do controle e seus agentes, Costa Lima faz uma avaliação do discurso ficcional no século XIX. Como se sabe, dois grandes movimentos irão aparecer como norteadores da ficção nesse período: o Romantismo e o RealismoNaturalismo.

Sobre o primeiro, o crítico chega a conclusão de que as instâncias 
políticas se apropriaram do literário para fazê-lo porta-voz do projeto liberal-nacionalista que começava a dominar a mentalidade da época. É assim que o Romantismo irá representar para a América Latina um movimento de construção da identidade nacional. Em nada de mau isso incorreria, se não fosse o fato do compromisso político muitas vezes sobrepujar a criação literária, cobrando-se dos escritores uma fidelidade excessiva a determinadas propostas políticas. Costa Lima analisa alguns escritores românticos latino-americanos e encontra na figura de José Martí, o poeta cubano, um traço interessante. Martí, embora engajado nas lutas de independência de Cuba (hoje é considerado herói nacional naquele país) é lúcido o suficiente para saber que a responsabilidade de construir a imagem da nação que é exigida dos escritores não é uma responsabilidade neutra e suas reflexōes sobre isso só não vão além porque Martí é restringido pelo espaço limitado de seus artigos jornalísticos. Na lucidez de Martí, Costa Lima vê uma forma de denúncia do controle a que estavam submetidos os escritores engajados. ${ }^{2}$

Voltando-se para o Brasil, o crítico mostra um momento interessante de nosso Romantismo. Escolhe para examinar algo peculiar: os discursos de Joaquim Nabuco, um liberal aguerrido, contra os romances e as peças teatrais de José de Alencar. Como se sabe, a obra de Alencar é uma obra de fundação da nossa nacionalidade. E isso é incontestável até que Nabuco, de sua tribuna, tenta mostrar como a ficção alencarina é inverossímil. Nabuco pergunta até que ponto ela cumpre de fato um papel construtor, até que ponto ela documenta de fato a nossa essência. Claro que não o faz com essas palavras, mas a análise enunciativa de seu discurso é reveladora de seu pensamento. Costa Lima vê nas acusações de Nabuco uma forma de controle, pois o que de fato se verifica é uma cobrança da velha imitatio, da qual (talvez sem perceber) até certo ponto fugiu o autor de $O$ Guarani. Joaquim Nabuco acusa Alencar de conservador, mas mostrase muito mais conservador do que o escritor, pelo menos no que diz respeito às questões da literatura. ${ }^{3}$

Quanto ao segundo movimento, o Realismo-Naturalismo, este representou um momento de controle mais acirrado por representar na literatura o veículo do ideário positivista e evolucionista. Ideário este, já largamente entranhado na História e na Sociologia e cujas concepções

2. Cf. os tópicos "A problemótico intelectuol" e "Concepp̧̧o de literoturo" no copítulo "literatura e sociedode na Américo hispônica (século XIX e coméços do século XX)". In: LMA, 1986. p.69-185.

3. Cf. o tópico "Documento e nocionolidode no Brosil", no copítulo "Documento e ficçāo". In: LIMA, 1986. p.187-242. foram amplamente difundidas por militares e médicos, dominando o pensamento intelectual até as primeiras décadas do século XX. Apesar da rigidez controladora do Realismo-Naturalismo, que rejeitava toda literatura que não contivesse explicą̧óes científicas, as rupturas do cânon não deixaram de ocorrer. Lembre-se aqui as poéticas de Baudelaire, Mallarmé e Lautréamont, que descontroem a noção de função da literatura. À luz do teorema de nosso Crítico, pode-se dizer que o movimento realista-naturalista foi um dos momentos na trajetória do controle em que o ficcional mostrase como um apêndice do discurso dominante.

Como se viu em tudo que se expôs até aqui, Costa Lima escolhe a prática da comparação e um raciocínio dialético para demonstrar suas hipóteses. Esse raciocínio será mantido em relação aos agentes do controle, ou seja, o crítico irá tratar do fenômeno do veto entre os agentes sob a perspectiva da inversão. Se no controle de natureza teológica o agenciamento era feito pelos representantes da instituição religiosa, no controle de natureza secular o agenciamento é exercido pelos escritores e críticos do ficcional. Percorrendo a crítica e a ficção do século XX, Costa Lima toma como objeto de estudo algumas correntes críticas e alguns escritores cujo pensamento se mostrou norteador da criação literária, pelo menos em alguma época e lugar. Trataremos disso no próximo tópico deste trabalho.

Antes, porém, faço uma ressalva às considerações de Costa Lima sobre o Romantismo. Sem duvidar da validade de suas críticas sobre a apropriação do discurso literário pelo discurso liberal e da militância política dos escritores focalizados, em sua maioria deputados, senadores ou membros de partidos políticos, acredito que o saldo do período romântico é muito mais positivo do que negativo. Não exatamente pelo veio do ufanismo, da exaltação pura e simples da cor local, mas pela capacidade que alguns de nossos românticos demonstraram de captar e trabalhar com os elementos fantásticos dessa cor local e romper com a verossimilhança (como em Alencar, onde os índios, mais parecidos com cavalheiros medievais, não documentam fielmente a realidade, ou em Álvares de Azevedo, onde os elementos fantásticos da natureza são entremeados a uma expressiva teatralização do $\mathrm{Eu}$ ). Se não rompeu totalmente com o modelo literário europeu, indubitavelmente nosso Romantismo serviu como um húmus fértil para a literatura brasileira. 


\section{AS DUAS FACES DA MOEDA OU OS AGENTES DO CONTROLE}

Costa Lima aponta como agentes do controle do ficcional os críticos e teóricos da ficção e em alguns casos, os próprios ficcionistas. À primeira vista tal afirmação parece um contra-senso (pelos menos em relação aos segundos), mas o Crítico procura prová-la através do método comparativo e dialético, jogando com os contrários. Toda moeda tem duas faces e para nosso Crítico uma não deve ser ocultada em detrimento da outra. Tal e qual a droga que pode ser remédio ou veneno, dependendo de seu uso - o pharmakon platônico - assim pode ser também a postura dos críticos e teóricos e dos ficcionistas em relação ao ficcional, quando direcionam suas práticas por caminhos que acabam levando ao controle.

Nos dois livros que aqui venho citando, Costa Lima aponta vários exemplos de como o remédio vira veneno, em especial quando faz um balanço do new criticism americano e do desconstrucionismo de Derrida, ou quando analisa a obra e o papel de Jorge Luís Borges na literatura latino americana e no exercício do controle do ficcional.

A escolha de trabalhar com os exemplos de Derrida e Borges deve-se ao fato de que Costa Lima faz uma aproximação entre o filósofo e o escritor em suas análises.

Em primeiro lugar tratarei do desconstrucionismo para mostrar o controle entre críticos e teóricos do ficcional e em seguida ocupar-meei de Borges e sua poética descentradora.

\subsection{Um filósofo no (des)centro do texto}

No final da década de 60 e início dos anos 70 verificou-se uma espécie de revolução no pensamento ocidental. Essa revolução, operada no seio da linguagem, foi prenunciada pelos estudos do antropólogo Claude Lévi-Strauss, por sua vez influenciado pela lingüística saussuriana. A revolução estruturalista francesa trouxe à luz as teorias de Lacan, Foucault, Barthes e Derrida, preocupados com os mecanismos internos da linguagem e suas imbricações com as estruturas mentais, histórico-sociais e discursivas numa sociedade logocêntrica por excelência, como a sociedade ocidental.
Os estudos de Derrida concentram-se na linguagem escrita, uma vez que o filósofo se opõe à antiga concep̧̧ão filosófica de que a escrita é apenas um instrumento do qual os filósofos se utilizam para demonstrar suas idéias, suas verdades. Contrariamente a tal concepção, Derrida afirma que um texto de idéias é também retórico e poético pois é tão dependente da palavra quanto qualquer outro e necessita da escrita para expressar-se.

Tal percepção levou Derrida a criar o conceito de desconstrucionismo. Costa Lima localiza em um texto do próprio filósofo a definição do termo: desconstruir significa examinar a estrutura genealógica de cada termo que constitui um texto para, daí, verificar o que esse texto interditou ou dissimulou e questionar a relação entre o verdadeiro e o falso de suas declarações. A tematização das relações entre o verdadeiro e o falso inevitavelmente levará à desconstrução dos conceitos privilegiados de causa e origem. ${ }^{4}$

Derrida almeja resgatar a escrita do "posto subalterno a que foi relegada" pelo logocentrismo. Dentro dessa perspectiva cria os neologismos écriture (indicador da ausência do sujeito, do centro ou de uma verdade metafisicamente fundada), différance (simulador da presença de um referente) e iterabilidade (combatente da presença metafísica) e opõe-se a metáfora (tão cara a Aristóteles) por considerá-la um entrave à errância e ao deslizamento contínuo da linguagem.

Analisando essa face da moeda do pensamento de Derrida, Luiz Costa Lima diz que o desconstrucionismo operou a corrosão da hierarquia existente entre categorias textuais, quer se privilegiasse o texto filosófico, quer se privilegiasse o texto ficcional (como no new criticism onde tal privilégio chegou aos extremos da sacralização do texto literário, como demonstra nosso Crítico). As concepções de Derrida (inicialmente aplicadas à Filosofia) intro-duziram a possibilidade de penetrar no texto para lê-lo às avessas, além de mostrar que não há barreiras ou especificidades entre os diversos discursos, uma vez que todos eles dependem da palavra e da escrita. O Filósofo aboliu a distinção entre o sério (o discurso da razão) e o não-sério ou parasitário (o discurso da fiç̧ão) e desconstruiu o estatuto da verdade como centro. Costa Lima louva a capacidade de Derrida denunciar e demonstrar os mecanismos de poder inscritos na linguagem. Entretanto afirma que o Filósofo tem uma parcela de participação no controle do ficcional. Passa, então, a mostrar o outro lado da moeda.

4. Cf. o tópico "Crítico e teorio com o desconstrucionismo", no copitulo "A critico e o controle". In: LIMA, 1988. p.307-355. 
A participação do Filósofo no controle, segundo Costa Lima, está relacionada à assimilação e à adaptação das idéias de Derrida aos estudos literários. De acordo com nosso crítico essas adaptaçōes nem sempre foram feitas de maneira adequada, o que leva a análise literária a trilhar caminhos nos quais o objeto ou seja, a literatura, aparece diluído, algo fantasmal, no dizer de Costa Lima, visto a indefinição das territorialidades do ensaio e da ficção. Para referendar suas observações, nosso ensaísta localiza na obra de um dos mais proeminentes discípulos de Derrida - Geoffrey Hartmann - $a$ indefinição de critérios quanto às especificidades discursivas e a identidade do crítico literário. Hartmann não consegue resolver a bom termo esses impasses, preferindo deixar ao futuro a definição do dilema das fronteiras textuais e do lugar do crítico.

A desconstrução em termos absolutos representa para Costa Lima uma denúncia da ilusão de que as certezas são absolutas. Mas o crítico faz a seguinte ressalva:

...é uma denúncia que se mantém no nível do que desconstrói. É uma absolutidade negativa, paralela, conquanto inversa à absolutidade teológica ou a absolutidade da ciência."

Dizendo com outras palavras, o descentramento da verdade, a ausência de limites, a desconstrução absoluta de tudo, leva, na opinião de Costa Lima, à criação de um novo centro: o das não-verdades, instaurandose, desse modo, uma inversão na trajetória do controle. O que antes surge para fugir do controle acaba depois por se tornar agenciador desse mesmo controle a partir do momento em que seus pressupostos teóricos são utilizados indiscriminadamente ou quando assume um caráter teológico, isto é, passa a ser seguido de maneira dogmática sem que se aceite ser discutido ou questionado.

Utilizando o mesmo tipo de raciocínio binário, Costa Lima trata do controle entre os ficcionistas através da figura de Jorge Luís Borges, como se verá no tópico seguinte deste trabalho.

\subsection{Borges: a inversão do controlado}

Para demonstrar mais uma vez a existência do controle na América Latina, Luiz Costa Lima analisa uma poética da modernidade - a ficção de
Jorge Luís Borges - movimentando-se em duas direçōes. Para realizar o primeiro movimento, nosso crítico faz um levantamento das primeiras recepçōes críticas do trabalho de Borges na Argentina. Para concretizar o segundo, Costa Lima percorre a construção interna da poética borgiana.

A releitura da obra de Borges por Costa Lima visa unicamente a uma apreciação dessa obra à luz da problemática do controle, visto que nosso Crítico enxerga no autor argentino um caso de controle duplo, ou seja, o ficcionista, antes controlado pela severidade dos críticos, inverte sua posição e encarna o papel do agente do controle ficcional.

Investigando as críticas feitas a Borges nas décadas de 20 e 30 , Costa Lima percebe que são freqüentes as observaçōes do anti-realismo do escritor, visto que a crítica da época ainda estava presa ao cânone realista e não conseguia compreender uma obra desvinculada da documentação do real. Para desafinar o coro dos que acusavam Borges de ser elitista e colonizado umas poucas vozes se levantaram para dizer que os escritos borgianos inauguravam uma nova estilistica e possuíam inclinações filosóficas, o que para Costa Lima representa uma argumentação equivocada por parte dos defensores do autor de Inquisiciones. Além das cobranças quanto à argentinidade de Borges, seus adversários acusam-no de produzir uma obra vazia, que não valoriza o homem nem questiona a problemática humana. Ou nas palavras do próprio Costa Lima:

Eles partem do suposto de que, com figuras de cartolina, não criaturas de carne e osso, trabalhadas por um matemático sem fé, poderá constituir-se numa literatura perigosa. ${ }^{6}$

Borges, entretanto, fecha os ouvidos aos críticos e permanece insubmisso aos critérios da boa literatura, ou seja, aquela prestadora de serviços à humanidade, que "professa uma crença" e cujos textos "possuem unidade interna e por isso sua interpretação é única", correta, análoga ao texto, bem ao gosto da tradição grega.

$\mathrm{Na}$ viagem que empreende ao interior do texto borgeano, Costa Lima verifica que o escritor argentino rompe com essa tradição e inaugura um novo momento na literatura. Nosso crítico chega a essa conclusão examinando os elementos que compõem a ficção de Borges. Desses elementos, dois são constantes e citados de maneira direta ou indireta pelo escritor. São eles a Gnose e a Cabala. 
As referências à Gnose e à Cabala são entendidas por Costa Lima como uma clara rejeição da tradição filosófica clássica, da teologia monoteísta judaico-cristã e da razão iluminista, uma vez que Gnose e Cabala representam uma explicação mítica herética da estrutura cósmica. ${ }^{7}$

É dentro da concepção mítica gnóstica que o mundo para Borges é apresentado como produto de um sonho, algo irreal e o tempo um material plástico, capaz de ser moldado, onde só existe o presente, pois o passado e o futuro são uma coisa só. A negação do tempo representa segundo Costa Lima, a negação da História. Se o mundo e o tempo são simulacros, a realidade é virada ao avesso constituindo-se isso numa antiphysis, ou seja, numa contraposição ao mundo ordenado e harmônico da physis. A antiphysis borgiana, ensina Costa Lima, é uma radicalização do mito gnóstico com o qual, convém acentuar, Borges não tem nenhum compromisso religioso; seu compromisso é única e exclusivamente estético. Da mesma forma que é estética sua concepção de metafísica uma vez que a define como um ramo da literatura fantástica, seu interesse é apenas literário. Tudo que toca vira ficção.

Além de negar a História, Borges nega também a Psicologia, pois seus personagens sem profundidade são uma negação do eu individualizado. Essas negações mostram claramente que a ficção borgiana se assume como fingimento, artifício, simulacro.

Por fim a pergunta: em tudo que aqui se expôs, onde está o controle? Costa Lima explica que o controle passa a existir quando a literatura rejeita tudo que não lhe sirva como matéria-prima; quando a ficção e o ensaio se fundam num único texto, no qual não se distingue o que é invenção e o que é juízo valorativo. Convertida em pura textualidade, interessada apenas por ela mesma, a ficção torna-se, assim, controladora pois institui uma nova verdade: tudo é ficção. Desconstrói o antigo centro - o modelo clássico - para tornar-se o novo modelo do discurso ficcional. Borges traz para a literatura a écriture assim como Derrida a trouxe para a crítica e a teoria.

A aproximação entre Derrida e Borges, como diz Eneida M. de Souza, se faz pelo traço devorador de ambos, que abafa a distinção entre ensaio, ficção e teoria ou como acrescenta a autora:

7. A gnose, grosso modo, é umo heresia cristā, surgida no iníio do Cristionismo com o advento do orientalismo e se contrapōe aos mitos biblicos.
Borges e Derrida estavam, portanto, contribuindo para o reforço de teorias ligadas à descontextualização da literatura e à hegemonia do discurso ficcional centralizado na sua própria autonomia, controlando outros discursos. ${ }^{8}$

Abafar a distinção discursiva significa para Costa Lima negar a di-ferença que tanto Borges quanto Derrida se encarregaram de demonstrar.

\section{CONCLUSÃO}

As proposições apresentadas por Costa Lima em relação ao que ele chama de controle do ficcional, indubitavelmente, representam um exaustivo trabalho de pesquisa que envolve considerações históricas e filosóficas para contextualizar suas reflexões e nisso o Crítico mostra-se filiado, ainda que de maneira peculiar, a uma tradição inaugurada por Antonio Candido, como bem lembra Eneida M. de Souza em seu ensaio citado há pouco. As análises de Costa Lima são sempre contextualizadas e atualizadas na perspectiva em que se inscrevem, mostrando-se radicais em alguns aspectos talvez até por trazerem à luz discussões sobre temáticas ainda difusas como a da inversão do lugar do controlador, cujos exemplos aqui foram Borges e Derrida mas poderiam ter sido T.S. Elliot e os new critics, uma vez que estes também são objeto de estudo de nosso Crítico.

Quanto à questão das especificidades discursivas, nosso Crítico tanto as reclama por considerar que o discurso crítico é um discurso indicativo, fundador de juízos de valor, que não é superior nem inferior ao discurso ficcional, que pode ser criativo sem se converter em ficção e possuir rigor metodológico e teórico sem, contudo, reivindicar o estatuto de ciência, como queriam os new critics. Eis aqui o que chamo de $3^{a}$ via de Costa Lima. Para nosso crítico, é necessário explicitar as diferenças.

Sobre isto considero que o ensaio crítico sem fronteiras pode também ser visto por dois ângulos: se por um lado ele quebra a rigidez do texto acadêmico, por outro lado, restringe sua capacidade de ser amplamente compreendido por outras categorias de leitores que não sejam iniciados nesse tipo de texto. Tal restrição poderia vir a ser um novo tipo de veto, pois a parcela de público leitor não iniciado teria dificuldades para

8. SOUZA, 1992.p.23 
distinguir entre o que é análise crítica e o que é ficção e nisso o conteúdo analítico se diluiria, tornando mais uma vez a figura do analista da literatura uma presença dispensável ou marginal, como diria Costa Lima.

Faz-se necessário, pois, saber dosar esse pharmakon, para que não se torne veneno. Quanto ao caso da ditadura da 'écriture' de Borges, perguntome se a nova colonização praticada pelo escritor não terá sido necessária para abalar o etnocentrismo reinante na literatura, revelando-se como o desvio necessário, como a presença dessemelhante, fazendo com que o Outro seja conhecido pelo Mesmo, como também o fizeram - só que por outra vertente, a do fantástico, do real maravilhoso, do barroquismo-os cubanos Alejo Carpentier e Lezama Lima, ou ainda Júlio Cortázar, Juan Rulfo e Gabriel García Marquez, com suas literaturas visivelmente desviadas do paradigma europeu.

Sobre Derrida, entretanto, falta-me cabedal teórico suficiente para refutar ou referendar completamente os argumentos de Costa Lima. O que fiz aqui foi uma compilação das discussões engendradas por nosso Crítico. Sei, contudo, que determinadas teorias não são a solução para todos os nossos impasses intelectuais, só por que não são arcaicas ou autoritárias, como dizem alguns referindo-se a outras correntes do pensamento com as quais não comungam. Teorias mal digeridas ao invés de apresentarem saídas, acabam criando novas encruzilhadas no labirinto. Idéias não são batatas fritas, como nos ensinou Barthes, quando enunciou seu desejo de não ser consumido pura e simplesmente. Sei, finalmente, que as noçōes de diferença e alteridade introduzidas por Derrida na sociedade ocidental foram valiosas para que se reconhecesse a (co)existência do desigual. E esse é seu grande contributo, seu grande salto.

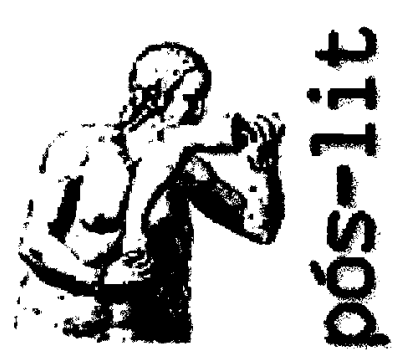

\section{Programa de Pós-Graduação em Letras: Estudos Literários da Faculdade de Letras da UFMG}

\author{
Artigo disponível em \\ http://www.letras.ufmg.br/poslit
}

REFERÊNCIAS BIBLIOGRÁFICAS

LIMA, Luiz Costo. Sociedade e discurso ficcional. Rio de Janeiro: Guanoboro, 1986.

1980.

50U2A, Eneido Mario de. Luiz Costo Limo: cútico em polimpsesto. Cadernos de pesquisa, Belo Horizonte, NAPQ/FALENUFMG, n. 7 , 1992. 